\title{
MICROBIAL TRANSFORMATIONS OF PLUTONIUM AND OTHER ACTINIDES IN TRANSURANIC AND MIXED WASTES
}

\author{
A.J. FRANCIS \\ Environmental Sciences Department \\ Brookhaven National Laboratory, Upton, New York 11973, USA
}

The presence of the actinides $\mathrm{Th}, \mathrm{U}, \mathrm{Np}, \mathrm{Pu}$, and $\mathrm{Am}$ in transuranic (TRU) and mixed wastes is a major concern because of their potential for migration from the waste repositories and long-term contamination of the environment. The toxicity of the actinide elements and the long half-lives of their isotopes are the primary causes for concern. In addition to the radionuclides the TRU waste consists a variety of organic materials (cellulose, plastic, rubber, chelating agents) and inorganic compounds (nitrate and sulfate). Significant microbial activity is expected in the waste because of the presence of organic compounds and nitrate, which serve as carbon and nitrogen sources and in the absence of oxygen the microbes can use nitrate and sulfate as alternate electron acceptors. Biodegradation of the TRU waste can result in gas generation and pressurization of containment areas, and waste volume reduction and subsidence in the repository. Although the physical, chemical, and geochemical processes affecting dissolution, precipitation, and mobilization of actinides have been investigated, we have only limited information on the effects of microbial processes.

Microbial activity could affect the chemical nature of the actinides by altering the speciation, solubility and sorption properties and thus could increase or decrease the concentrations of actinides in solution. Under appropriate conditions, dissolution or immobilization of actinides is brought about by direct enzymatic or indirect non-enzymatic actions of microorganisms. Dissolution of actinides by microorganisms is brought about by changes in the Eh and $\mathrm{pH}$ of the medium, by their production of organic acids, such as citric acid, siderophores and extracellular metabolites. Immobilization or precipitation of actinides is due to changes in the Eh of the environment, enzymatic reductive precipitation (reduction from higher to lower oxidation state), biosorption, bioaccumulation, biotransformation of actinides complexed with organic and inorganic ligands and bioprecipitation reactions. Free-living bacteria suspended in the groundwater fall within the colloidal size range and may have strong radionuclide sorbing capacity, giving them the potential to transport radionuclides in the subsurface.

The actinides in TRU and mixed wastes may be present in various forms, such as elemental, oxide, coprecipitates, inorganic, and organic complexes, and as naturally occurring minerals depending on the process and waste stream. They exist in various oxidation states and the ones of concern are III ( $\mathrm{Am}, \mathrm{Pu}, \mathrm{U}), \mathrm{IV}(\mathrm{Th}, \mathrm{Pu}, \mathrm{U}), \mathrm{V}(\mathrm{Np})$, and VI (Pu, U). Microorganisms have been detected in TRU wastes, Pu-contaminated soils, low-level radioactive wastes, backfill materials, natural analog sites, and waste-repository sites slated for high-level wastes ${ }^{1}$. Seventy percent of the TRU waste consists of cellulose and other biodegradable organic compounds. Biodegradation of cellulose under the hypersaline conditions such as in the WIPP repository can produce $\mathrm{CO}_{2}$ and methane gas, as well as affect the solubility of actinides. Microbially produced gases could have significant ramifications for the long-term stability of the repository (up to 10,000 years). Little is known of microbial degradation of organic constituents in TRU and

*This work was performed under the auspices of the U.S. Department of Energy. 
mixed wastes and its implications on gas generation and the fate of actinides i.e., mechanisms of the dissolution and precipitation of actinides.

Chelating agents are present in TRU and mixed wastes because they are widely used for decontaminating nuclear reactors and equipment, in cleanup operations, and in separating radionuclides. Plutonium forms very strong complexes with a variety of organic ligands. Naturally occurring organic complexing agents, such as humic and fulvic acids, and microbially produced complexing agents, such as citrate, and siderophores, as well as synthetic chelating agents can affect the mobility of $\mathrm{Pu}$ in the environment. Biotransformation of actinide-organic complexes should result in the degradation of the organic ligand and precipitation of the actinide.

Key microbial processes involved in the mobilization or immobilization of selected actinides of interest is summarized in Table 1. Among the actinides, biotransformation of uranium has been extensively studied, whereas we have only limited understanding of the microbial transformations of other actinides such as Th, $\mathrm{Np}, \mathrm{Pu}$, and $\mathrm{Am}$ present in TRU and mixed wastes ${ }^{1,2}$.

Table 1. Biotransformation of Selected Actinides in TRU and Mixed Wastes.

\begin{tabular}{|c|c|c|c|c|c|}
\hline Process & $\mathrm{Th}$ & $\mathrm{U}$ & $\mathrm{Np}$ & $\mathrm{Pu}$ & Am \\
\hline Oxidation ${ }^{1}$ & NA & ++ & ND & ND & NA \\
\hline Reduction $^{2}$ & NA & ++++ & $+?$ & $+?$ & NA \\
\hline Dissolution $^{3}$ & + & ++ & $?$ & + & $?$ \\
\hline Biosorption & $?$ & ++++ & + & ++ & + \\
\hline Biocolloid $^{4}$ & + & ++ & + & + & + \\
\hline
\end{tabular}

NA- not applicable; ND- not determined.

${ }^{1}$ Dissolution due to oxidation from lower to higher valence state.

${ }^{2}$ Reductive precipitation due to enzymatic reduction from higher to lower valence state.

${ }^{3}$ Dissolution due to oxidation from lower to higher valence state, changes in $\mathrm{pH}$, production of organic acids and sequestering agents such as siderophores.

4- Association of radionuclides with suspended bacteria, which can be potentially transported as biocolloids.

The effects of microbial activities on TRU and mixed waste and their potential for treatment of certain waste forms to stabilize the actinides and reduce the volume of the waste have not been fully exploited. Fundamental understanding of the mechanisms of microbial transformations of several chemical forms of actinides under various microbial process conditions such as aerobic, anaerobic (denitrifying, fermentative, and sulfate reducing) and repository relevant conditions would pave the way to assess the microbial impact on TRU wastes 
and the long-term behavior of actinides in the environment. In this paper biotransformation of actinides, in particular Pu under various microbial process conditions is presented.

\section{References}

1. Francis, A.J. 2001. Microbial transformations of plutonium and implications for its mobility. In "Plutonium in the Environment" A. Kudo, (Ed) Elsevier Science Ltd., Co., UK. Pp 201219.

2. Neu, M.P., C.E. Ruggiero, and A.J. Francis. 2002. Bioinorganic Chemistry of Plutonium and Interactions of Plutonium with microorganisms and Plants. In "Advances in Plutonium Chemistry 1967-2000" D. Hoffman (Ed), pp 169-211. Published by American Nuclear Society, la Grange Park Illinois and University Research alliance, Amarillo, Texas. 